\title{
Adolescent Marital Expectations and Romantic Experiences: Associations With Perceptions About Parental Conflict and Adolescent Attachment Security ${ }^{1}$
}

\author{
Sara J. Steinberg, ${ }^{2}$ Joanne Davila, ${ }^{3}$ and Frank Fincham ${ }^{4}$ \\ Received June 28, 2004; revised May 3, 2005; accepted May 9, 2005 \\ Published online: 3 May 2006
}

\begin{abstract}
This study tested associations between adolescent perceptions of interparental conflict, adolescent attachment security with parents, and adolescent marital expectations and romantic experiences. Participants were 96 early adolescent females from 2 parent families. Insecurity was examined as a mediator of the association between negative perceptions of parental conflict and romantic outcomes. Results supported the mediation model in which adolescents' negative perceptions of parental conflict was associated with insecure attachment with parents, which was in turn associated with negative marital expectations and romantic experiences. Implications for understanding how parent-adolescent and interparental variables influence adolescent marital expectations and romantic experiences are discussed.
\end{abstract}

KEY WORDS: adolescent; attachment; dating; interparental conflict; romantic.

\section{INTRODUCTION}

The ability to develop intimate relationships is a pivotal developmental task in adolescence that has implications for successful functioning (Berscheid, 1999). Close social connections enhance psychological well-being, and the inability to develop or maintain successful romantic

\footnotetext{
${ }^{1}$ Portions of this paper were presented at the 2002 biennial meeting of the Society for Research on Adolescence in New Orleans, LA. This research was based in part on the first author's master's thesis.

${ }^{2}$ Doctoral candidate in Department of Psychology, State University of New York at Stony Brook. Received MA in Psychology from SUNY Stony Brook. Current research interests include romantic functioning, family relationships, and psychopathology in adolescence. To whom correspondence should be addressed at Department of Psychology, SUNY Stony Brook, Stony Brook, New York 11794-2500; email: sara.j.steinberg@sunysb.edu.

${ }^{3}$ Associate Professor of Psychology at State University of New York at Stony Brook. Received $\mathrm{PhD}$ in Psychology from University of California, Los Angeles. Major research interests focus on the interplay of close relationships and psychopathology in adolescence and adulthood.

${ }^{4}$ Eminent Scholar and Director of Florida State University Family Institute. Received DPhil in Social Psychology from Oxford University. Current research interests include relationship development, forgiveness in relationships, and marital processes.
}

relationships is associated with emotional and physical distress (e.g., Simon and Marcussen, 1999). As these links between romantic functioning and well-being have become clear, researchers have begun to explore how the capacity for romantic competence develops. It has been hypothesized that a child's earliest experiences in relationships, whether as an observer or a participant, may serve as a template for later romantic relationships (e.g., Gray and Steinberg, 1999). For instance, a family environment marked by parental warmth, structure, and emotional availability may promote in the adolescent a healthy, enduring ability for intimacy and relatedness (Collins and Sroufe, 1999; Furman and Wehner, 1994). Research is now beginning to support such claims. For example, one longitudinal study, which included observational ratings of family interactions, and followed adolescents from 7th grade to adulthood, found that nurturant-involved parenting in early adolescence predicted romantic behaviors in late adolescence that were warm, supportive, and low in hostility (Conger et al., 2000).

If early experiences with parents predict later romantic relationship behavior, it is important to investigate the specific types of family experiences that may do so. This study was designed to examine how 
marital and parent-adolescent relations contribute to the development of adolescent marital expectations and romantic experiences. Specifically, we investigated how adolescent perceptions of interparental conflict and how the attachment relationship between adolescents and their parents affect adolescent romantic activity and marital expectations.

The importance of adolescent's attachment security with parents for understanding marital expectations and romantic experiences is emphasized by Bowlby's (1969) theory. According to Bowlby, individuals develop internal working models based on early caregiving experiences that then guide their expectations and attitudes in other, later relationships. From this perspective experiences in the parent-child relationship therefore have implications for how the adolescent thinks, feels, and behaves in other relationships, including romantic relationships. Although little research exists with regard to romantic relationships specifically, in the peer domain there is evidence that late adolescents who reported secure relationships with their parents had lower levels of emotional distress and higher levels of social support, and were rated by their peers as more ego-resilient, less anxious, and less hostile (Kobak and Sceery, 1988). Current theorists suggest that parentchild experiences also have implications for how the adolescent interacts with romantic partners and how the adolescent interprets behaviors and attitudes of the romantic partner (e.g., Welsh et al., 2003).

To examine parent-child attachment security, we drew on recent conceptualizations of attachment working models (e.g., Bartholomew and Horowitz, 1991; Collins and Read, 1990). Many attachment scholars postulate that two dimensions underlie attachment patterns. One dimension, anxiety about abandonment, reflects people's model of the self, such that people who view the self as worthy experience little fear that others will abandon them (indicative of security), whereas people who view the self as unworthy experience great fear that they will be abandoned (indicative of insecurity). The other dimension, avoidance of intimacy, reflects people's model of others, such that people with a more positive model of others are comfortable being intimate with others and tend to seek out closeness (indicative of security), whereas people with a more negative models of other are uncomfortable with intimacy and tend to avoid close relationships (indicative of insecurity). We examined the extent to which adolescents' anxiety about abandonment and avoidance of intimacy in the context of the parent-child relationship were associated with their marital expectations and romantic experiences.

In addition to parent-child attachment security, perceived interparental relations may also play a role in adolescent romantic development. Specifically, adolescent perceptions of interparental conflict may be important for understanding adolescent romantic activity because the observation of the parental relationship is one way that adolescents may learn about romantic relationships. If adolescents observe that their parents are emotionally unavailable with one another, or unable to resolve conflicts, then they may be more likely to exhibit similar characteristics both in the home and in other social arenas (Emery, 1982). A number of studies support this idea. For example, parental marital satisfaction, which may reflect poor conflict resolution and affect regulation, is related to adolescent females' self-esteem, frequency of dating, and degree of seriousness with present boyfriend (Long, 1986; 1987). In addition, perceived interparental conflict is associated with adolescents' poor conflict resolution strategies with romantic partners (e.g., Reese-Weber and Bertle-Haring, 1998), although this association appears to be mediated by parent-adolescent factors.

The goal of the study was, therefore, to examine whether perceptions of interparental conflict and adolescent attachment security with parents were associated with adolescent romantic functioning. It is possible that interparental conflict and attachment security with parents are each unique predictors of adolescent romantic functioning because each may be a model of intimate relationships for a developing adolescent. Therefore, attachment models indicative of insecurity (i.e., high levels of anxiety about abandonment and low levels of comfort with intimacy) and perceptions of interparental conflict should each be associated with more maladaptive marital expectations and romantic experiences. In addition, there is reason to believe that that these factors may work together in influencing adolescent romantic development because interparental factors and parent-adolescent factors are related. For example, there is a great deal of evidence supporting the link between marital conflict and parent-child attachment insecurity (e.g., Howes and Markman, 1989; Owen and Cox, 1997). Therefore, it is likely that perceptions of interparental conflict would be associated with insecurity in the adolescent-parent relationship. Given this, we examined whether insecurity mediated the relationship between interparental conflict and romantic outcomes.

Mediation is commonly defined as a situation in which 1 variable influences another through an intervening variable (Baron and Kenny, 1986). We hypothesized that interparental conflict influenced romantic outcomes through attachment insecurity. Specifically, we predicted that negative perceptions about parental conflict set the stage for insecurity in adolescent-parent relations, which in turn results in more maladaptive adolescent marital expectations and romantic experiences (see Fig. 1). 


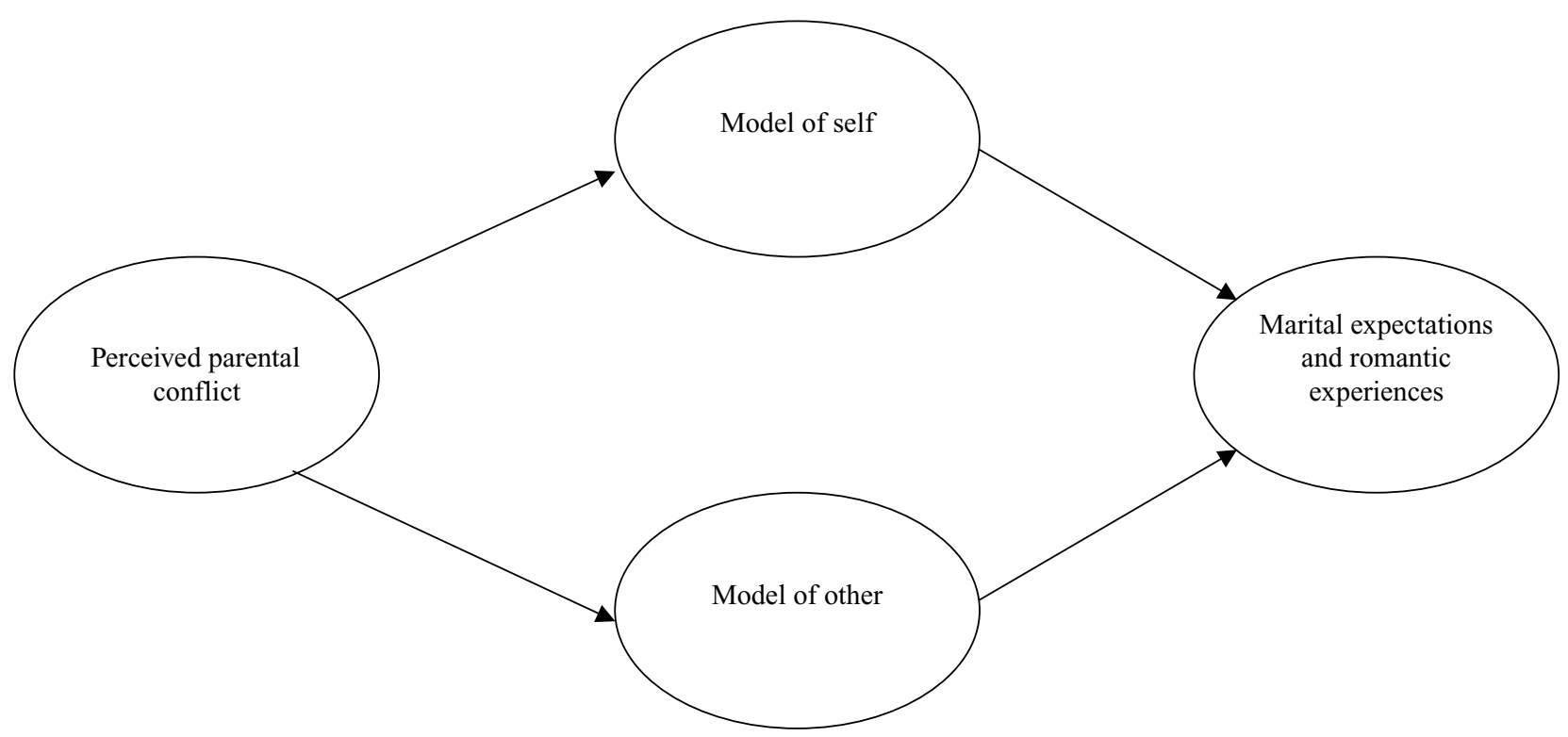

Fig. 1. Proposed mediation model of adolescent attachment security as a mediator between perceived parental conflict and romantic expectations and experiences.

According to this model, interparental conflict may influence adolescent romantic activity indirectly through the parent-adolescent relationship. It has been suggested that the ways in which children perceive, interpret, and internalize marital relations (i.e., marital conflict) may influence children's psychological (or emotional) security, which would then have implications for their current and long-term functioning (Cummings and Davies, 1995; Davies and Cummings, 1994). According to the emotional security hypothesis, marital conflict may increase the negativity of parent-child interactions (i.e., parental rejection), or it may decrease parental involvement and emotional availability because the parent is emotionally occupied by the conflict (Davies and Cummings, 1994). The resulting emotional insecurity may shape adolescents' representations about romantic relationships, and influence their expectations about their own relationships. So according to this model, adolescents who hold negative perceptions about parental conflict are more likely to feel insecure in the adolescent-parent relationship. This insecurity will then guide their thoughts, feelings, and experiences in other relationships.

\section{Methodological Challenges}

In this study, we addressed 3 important methodological issues. There is disagreement about whether it is best to assess attachment security via self-report or interview, and evidence is beginning to emerge suggesting that security can have different correlates, depending on how it is assessed (Furman and Shaffer, 2002; Waters et al., 2002). Therefore, we included both self-report and interview measures in our study. Second, concerns have been raised about the use of a single reporter of familyrelated events. Although we have argued that it is adolescents' perceptions of interparental conflict that affect their romantic relationships because these perceptions are indicative of adolescents' cognitive-affective processing of events, it may also be the case that the events (i.e., the conflict) themselves may have an effect. To examine this possibility, parental report of conflict was also examined. Finally, we addressed the third variable problem, namely, that other individual or personality characteristics may account for the proposed relations between attachment security, perceptions of parental conflict, and the romantic outcomes. To address this possibility, we included a measure of neuroticism in our models (Watson and Clark, 1984). We selected neuroticism because, as an indicator of generalized negative affectivity, it may account for both the tendency to perceive high levels of interparental conflict and the tendency to feel insecure in close relationships.

\section{Overview of Study}

This study investigated adolescent girls' marital expectations and romantic experiences. In terms of expectations, we studied how unhappy, or dissatisfied, the 
adolescents predicted they will be in their future marriages and the likelihood that they think they will get divorced. These may be important variables because adolescent marital expectations may shape the outcome and satisfaction of their future romantic relationships. It can be argued that early adolescents may be too young to have realistic expectations about their romantic future. However, research on the self-fulfilling prophecy suggests that people's expectations influence the reality of their relationships (Downey et al., 1998; Murray et al., 1996). Furthermore, evidence suggests that women with rejection expectations act in romantic relationships in ways that elicit rejecting responses from their partners. Although this research involves adults, it has been suggested that a similar model can be applied to adolescents, particularly girls, in which expectations for rejection influence how adolescents think, feel, and behave in romantic relationships (Downey et al., 1999). This research suggests that early adolescents' expectations regarding future romantic happiness may in fact influence their behavior in future romantic relationships.

We examined a number of romantic experiences ranging from potentially normative experiences to potentially risk-taking or maladaptive experiences. Items were chosen to include a representation of approachoriented experiences, potentially rejecting experiences, and risk-taking experiences for early adolescent girls. During early adolescence, romantic relationships are less common. Therefore, romantic/sexual experiences and attitudes may be the best indicators of romantic functioning for early adolescents. Early adolescents who engage in maladaptive romantic behaviors, or who become sexually or romantically involved prior to their peers may be more at risk for future romantic difficulties. Thus, examining a range of romantic/sexual experiences in early adolescence is crucial.

We expected that adolescent-parent attachment security and perceptions of interparental conflict would be associated with adolescent marital expectations and romantic experiences. In addition, we predicted that negative perceptions about parental conflict set the stage for insecurity in adolescent-parent relations, which in turn predict negative adolescent marital expectations and romantic experiences.

The mediation model was tested using structural equation modeling (SEM), which provides a parsimonious way to test regression-based path models and mediation. Constructs in the model were specified as measured variables because of sample size and hence our data analyses do not benefit from the advantages of latent variable modeling. However, to confirm that our measured variables were psychometrically sound, we subjected them to confirmatory factor analyses before including them in the models. This will be described in detail in the results section.

\section{METHOD}

\section{Participants}

Participants were 96 early adolescent girls from the greater Buffalo, New York area who were participating with their parents in an ongoing study of family and adolescent relationships. All girls came from intact 2-parent families. We studied girls because they tend to be more interested in and attuned to romantic relationships than are boys (e.g., Shulman and Scharf, 2000). In addition, girls are at increased risk for psychological problems (e.g., depression) that were being investigated in the larger study from which this data set is derived. The families were recruited through advertisements and from a local middle school. Four hundred letters were mailed to families of 8 th grade daughters in a local middle school. Families were instructed to return a postage paid postcard if they were interested in participating. Seventy-seven postcards were returned (19\%). Of them, 31 families who were eligible participated. Advertisements were also placed in local newspapers, on cable television, and in the community. Interested families were asked to call the project. Two hundred forty-eight families were interested and, of them, 65 who were eligible participated. Eligibility criteria included being an intact family with an 8th grade daughter with the ability to read and comprehend questionnaires and participate in computer tasks. Families with daughters with severe learning disabilities that would impair their performance were excluded. The girls' average age was 13.24 years $(\mathrm{SD}=0.5)$. Ninety-one percent were in the 8th grade and $91 \%$ described themselves as White. Their fathers were 43.1 years old on average $(\mathrm{SD}=4.46)$ and predominantly White (97\%). Forty-five percent reported graduating high school and $51 \%$ reported a college or postgraduate education. Mothers were 41.12 years old on average $(\mathrm{SD}=4.74)$ and predominantly White $(98 \%)$. Forty-two percent reported graduating high school and $57 \%$ reported a college or postgraduate education. Median family income was in the range of $\$ 51,000$ to $\$ 60,000$.

\section{Procedure}

This study was part of a larger ongoing project examining family and adolescent relationships. The families participated in a lab session that took place at the 
University of Buffalo, the State University of New York. During the sessions, the parents completed questionnaires concerning their self-report of marital conflict while the girls privately completed questionnaires assessing attachment security, perceived interparental conflict, marital expectations and romantic experiences, and neuroticism. In addition, the girls were privately interviewed about their attachment security. The families were paid $\$ 75$ for participation.

\section{Measures}

\section{Attachment Security}

Attachment security was assessed with both selfreport and interview measures. Self-reported security was assessed using the Relationship Questionnaire (RQ; Bartholomew and Horowitz, 1991), which contains multisentence descriptions of attachment patterns (secure, preoccupied, fearful, and dismissing). The descriptions are each rated on a 7-point continuous scale assessing how well each resembles the participants' relationship styles with their parents. Participants were asked to rate their attachment style with their mother and father separately. Following Bartholomew and Horowitz (1991), 2 scales were computed that represent the underlying dimensions of security discussed earlier. The 1st scale, which Bartholomew called model of self, was computed by summing the ratings of the secure and dismissing attachment patterns (which reflect positive self models) and subtracting from that sum the ratings of preoccupied and fearful attachment patterns (which reflect negative self models). This scale reflects anxiety about abandonment, such that people with a more positive model of self are less anxious than people with a more negative model of self. The 2nd scale, which Bartholomew called model of other, was computed by summing the ratings of the secure and preoccupied attachment patterns (which reflect positive other models) and subtracting from that sum the ratings of the dismissing and fearful attachment patterns (which reflect negative other models). This scale reflects avoidance of intimacy, such that people with a more positive model of others are more comfortable with intimacy than are people with a more negative model of others. Although the RQ is only a 4-item measure, adequate psychometric properties have been reported, including good construct validity (e.g., Bartholomew and Horowitz, 1991; Shaver and Mikulincer, in press). Although the bulk of this evidence comes from studies of adults, Collins et al. (2002) successfully used a similar measure (the Hazan and Shaver three-paragraph measure; Hazan and Shaver, 1987) with a large sample of adolescents. Furthermore, our own data set demonstrates preliminary psychometric properties for the RQ in an adolescent sample (Davila et al., 2004).

The interview measure of security was the Family Attachment Interview (FAI; Bartholomew, 1998; Bartholomew and Horowitz, 1991). The FAI is a semistructured interview designed to assess adolescent attachment styles based on information about the adolescents' parents. The procedures and scoring of the FAI are similar to that of the Adult Attachment Interview (AAI; George et al., 1985), except that the FAI codes people on 4 attachment patterns (secure, fearful, preoccupied, and dismissing), rather than the 3 categories used in the AAI (secure, preoccupied, and dismissing). The FAI attachment ratings are similar to the AAI in that they are based on content of reports as well as reporting style (e.g., coherency of the report). Interviews were coded for each attachment style on a 9-point scale ranging from 1 (no evidence of characteristics of the prototype) to 9 (near perfect fit with the prototype). The interview asks about relationships with both parents and coders are instructed to take all information into consideration when making ratings. Coders included the 1st and 2nd authors, and another graduate student. The coders were blind to the participants' status on all other variables and were trained to reliability by the 2 nd author. The reliability coefficients $(\alpha)$ for 18 randomly selected participants coded by 2 raters were: 0.70 for secure, 0.85 for fearful, 0.75 for preoccupied, and 0.86 for dismissing. As with the RQ, 2 dimension of security were computed: model of self and model of other.

\section{Children's Perception of Interparental Conflict Scale (CPIC)}

The CPIC (Grych et al., 1992) is a 51-item selfreport measure that assesses perceived dimensions of interparental conflict (frequency, intensity, resolution, content, and stability of the causes of conflicts) and children's reaction to the conflict (self-blame, threat, coping efficacy, and triangulation, or a feeling of being drawn into the conflict). Subscales have demonstrated acceptable internal consistency on 2 separate samples of 4th and 5th grade children (coefficient $\alpha$ averaged 0.73; range 0.610.83 ) and yielded 3 stable, higher order subscales: conflict properties, threat, and self-blame with corresponding $\alpha$ s of $0.89,0.83$, and 0.84 , and 2-week test-retest reliabilities of $0.70,0.68$, and 0.76 , respectively (Grych et al., 1992). Bickam and Fiese (1997) have reported similar reliability and validity data using the CPIC with 
adolescents. In our sample, the subscales of conflict properties, threat, and self-blame yielded corresponding $\alpha \mathrm{s}$ of $0.91,0.85$, and 0.80 . The total scale (a composite measure of these 3 subscales) yielded an $\alpha$ of 0.93 . Due to the strong inter-item reliability of the composite measure of the 3 subscales and because specific predictions were not made about the subscales, the total scale was used in the analyses. This is in line with recommendations made by the scale's developers (see Harold et al., 1997). Higher scores on this measure indicate perceptions of parental conflict as frequent, intense, without resolution, and also that the adolescents react to the conflict negatively (e.g., blame themselves, feel drawn into the conflict).

\section{Parental Perception of Marital Conflict Scale}

This is a 12 -item measure that assesses spousal report of interparental conflict. The questions are adapted from the CPIC (Grych et al., 1992) and reworded for married couples. The items ask about similar topics as the CPIC including questions pertaining to conflict intensity ("we tend to get really angry when we argue or disagree"), resolution ("when we argue, we often make up right away"), and frequency ("we hardly ever argue or disagree"). In our sample of parents, the scale yielded an $\alpha$ of 0.81 for mothers, and 0.86 for fathers.

\section{Marital Expectations}

The marital expectations measure was designed for this study and assesses the adolescents' expectations for future happiness and success in marriage. This measure consisted of 5 items $(\alpha=0.76)$. Two questions assessed the adolescents' predictions for happiness/satisfaction in their future marriage ("Overall, how happy do you think you will be in your marriage?" and "Overall, how satisfied do you think you will be in your marriage?"). A separate question asked, "How likely is it that you think you will be unhappy at any point in your marriage?" Each of these questions had likert scales ranging from 1 (very unlikely) to 7 (very likely). In addition, 2 questions assessing the adolescents' predictions for likelihood of divorce were included. The 1st question, "What do you think the chances are that you will get divorced some day?" had a response scale of $0-100 \%$. The 2 nd question, "How likely is it that your 1st marriage will end in divorce?" had a Likert scale of 1-7. As described in the CFA section, we initially tested this measure as 1 latent construct.

\section{Romantic Experiences}

The romantic experiences measure, also designed for this study, consisted of 6 items reflecting experiences ranging from potentially normative to potentially risky/maladaptive $(\alpha=0.74)$. Three items (asking someone out on a date, having gone on a bad date, and having been turned down for a date) could represent experiences that are potentially normative or, in the case of the latter 2 , potentially rejecting. The response scales for asking someone out on a date and having been turned down for a date ranged from 1 (never) to 4 (many times), whereas the response scale for having gone on a bad date ranged from 1 (never) to 3 (frequently). Three items (dating a married person or someone involved in another relationship, having been coerced into sexual relations, and engaging in sexual relations that are more than kissing, but not intercourse) could represent potentially risky or maladaptive experiences. The response scale for the 1st 2 questions ranged from 1 (never) to 4 (many times), whereas the response scale for engaging in sexual relations that are more than kissing but not intercourse ranged from 1 (never) to 3 (frequently). It should be noted that an item regarding sexual intercourse was included in the study, but omitted from the analyses because only 1 participant in our sample reported having had sexual intercourse. As described in the CFA section, we 1st tested all of the romantic experience variables as representative of 1 latent construct. However, we conceptualized the 3 risky variables as being related and expected that they would specifically correlate with one another. Indeed, they yielded an $\alpha$ of 0.85 . We are not suggesting that these specific items are the only items that would be uniquely related to interparental and parentadolescent factors. But rather, the particular items used in this study were chosen because they are representative of important aspects of early adolescent romantic/sexual functioning, and because they had high base rates in this sample.

\section{Neuroticism}

Adolescents completed the Mini-Markers (Saucier, 1994), a set of 40 adjectives based on Goldberg's (1992) set of 100 adjective markers for the Big Five factor structure. The response scale for the items was a 9-point continuous scale ranging from extremely inaccurate to extremely accurate. Reliability coefficients for the scales have been reported at about 0.80 (see Saucier, 2000). The current study used the 8 items representative of the neuroticism factor $(\alpha=0.67)$. 


\section{RESULTS}

\section{Overview of Data Analyses}

First, we conducted confirmatory factor analyses (CFAs) in order to examine whether the latent structures of our composite variables were supported. This was done using the structural equations modeling program AMOS (Arbuckle, 1997). Second, we conducted zero-order correlations between the composite variables derived from the CFAs to examine whether perceptions of interparental conflict and parent-adolescent attachment security were associated with each other and with the romantic variables. Then, we tested the 2 predicted mediation models for both the marital expectations and the romantic experiences, resulting in 4 models, using maximum likelihood estimation in AMOS. Model testing proceeded in the following steps. First, we examined the mediated associations without the direct effects. Second, where necessary, we re-estimated the model with non-significant paths deleted. Third, when appropriate, we included the direct effects and tested whether the models with and without the direct effects were significantly different. If not, this would suggest that the direct effects did not account for variance earlier that accounted for by the indirect effects, thereby supporting mediation. In the last step, we included neuroticism in the final mediation model to examine whether associations held when controlling for neuroticism.

\section{Confirmatory factor analyses}

As noted earlier, because our sample size could not accommodate full latent variable models, we included measured composite variables in the models, but subjected those composites to confirmatory factor analysis to examine their latent structure.

\section{Attachment Security}

Because we had multiple measures of security, we computed composite variables for model of self and model of other, which were composed of the self-report and interview scores for each dimension. To confirm the latent structure of this composite, 1 model was specified, which included a latent variable for model of self (indicated by the self-report model of self score for mothers, the self-report model of self score for fathers, and the interview model of self score) and a latent variable for model of other (indicated by the self-report model of other score for mothers, the self-report model of other score for
Table I. Factor Loadings for the Confirmatory Factor Analyses

\begin{tabular}{|c|c|c|}
\hline CFAs with paths & $\beta$ & $p$ value \\
\hline \multicolumn{3}{|l|}{ Security } \\
\hline \multicolumn{3}{|l|}{ Model of self } \\
\hline $\begin{array}{l}\text { Model of self -> self-report model of self with } \\
\text { mother }\end{array}$ & 0.66 & $-^{a}$ \\
\hline $\begin{array}{l}\text { Model of self -> self-report model of self with } \\
\text { father }\end{array}$ & 0.97 & 0.00 \\
\hline Model of self -> interview model of self & 0.35 & 0.00 \\
\hline \multicolumn{3}{|l|}{ Model of other } \\
\hline $\begin{array}{l}\text { Model of other -> self-report model of other } \\
\text { with mother }\end{array}$ & 0.60 & $-^{a}$ \\
\hline $\begin{array}{l}\text { Model of other -> self-report model of other } \\
\text { with father }\end{array}$ & 0.88 & 0.00 \\
\hline Model of other -> interview model of other & 0.30 & 0.01 \\
\hline \multicolumn{3}{|l|}{ Perceived parental conflict (CPIC) } \\
\hline CPIC -> frequency & 0.67 & $-^{a}$ \\
\hline CPIC -> intensity & 0.81 & 0.00 \\
\hline CPIC $->$ resolution & 0.72 & 0.00 \\
\hline CPIC -> content & 0.42 & 0.00 \\
\hline CPIC $->$ threat & 0.67 & 0.00 \\
\hline CPIC -> coping & 0.72 & 0.00 \\
\hline CPIC $->$ self-blame & 0.55 & 0.00 \\
\hline \multicolumn{3}{|l|}{ Marital expectations } \\
\hline \multicolumn{3}{|l|}{ Predictions for divorce } \\
\hline $\begin{array}{l}\text { Marital expectations -> chances of getting } \\
\text { divorced }\end{array}$ & 0.61 & 0.00 \\
\hline Marital expectations -> prediction for divorce & 0.70 & 0.00 \\
\hline \multicolumn{3}{|l|}{ Predictions for marital satisfaction } \\
\hline $\begin{array}{l}\text { Marital expectations -> predictions for marital } \\
\text { happiness }\end{array}$ & -0.51 & 0.00 \\
\hline $\begin{array}{l}\text { Marital expectations -> predictions for marital } \\
\text { satisfaction }\end{array}$ & -0.68 & 0.00 \\
\hline \multicolumn{3}{|l|}{ Prediction for marital unhappiness } \\
\hline $\begin{array}{l}\text { Marital expectations -> predictions for marital } \\
\text { unhappiness }\end{array}$ & 0.68 & $-^{a}$ \\
\hline \multicolumn{3}{|l|}{ Romantic experiences } \\
\hline $\begin{array}{l}\text { Marital experiences -> asked someone out on a } \\
\text { date }\end{array}$ & 0.74 & $-^{a}$ \\
\hline Marital experiences -> went on a bad date & 0.48 & 0.00 \\
\hline $\begin{array}{l}\text { Marital experiences -> was turned down for a } \\
\text { date }\end{array}$ & 0.72 & 0.00 \\
\hline \multicolumn{3}{|l|}{ Risk-taking experiences } \\
\hline $\begin{array}{l}\text { Marital experiences -> dated someone involved } \\
\text { in another relationship }\end{array}$ & 0.41 & 0.00 \\
\hline $\begin{array}{l}\text { Marital experiences -> engaged in sexual } \\
\text { relations }\end{array}$ & 0.54 & 0.00 \\
\hline $\begin{array}{l}\text { Marital experiences -> was coerced into sexual } \\
\text { relations }\end{array}$ & 0.35 & 0.01 \\
\hline
\end{tabular}

${ }^{a}$ As required by AMOS, these paths were fixed.

fathers, and the interview model of other score). The factors were allowed to correlate. This model provided an adequate fit to the data, $X^{2}(8)=12.70, p=0.12, \mathrm{CFI}=0.99$, $\mathrm{RMSEA}=0.08$. The factor loadings are presented in Table I. As can be seen, all factor loadings were significant, although the interview scores did not load as strongly as the self-report scores. The 2 factors were correlated 
$(r=0.46, p=0.02)$. These findings supported the use of the composites in further analyses.

\section{CPIC}

In order to confirm that the 7 subscales of the CPIC reflect the overarching construct, we conducted a CFA with 1 latent variable specified. It included scores on the 7 primary subscales of the CPIC (frequency, intensity, resolution, content, threat, coping, and self blame). Error terms were allowed to correlate to reflect the proposed 3 higher order subscales (Grych et al., 1992). Specifically, the error terms for frequency, intensity, and resolution were allowed to correlate; content and self-blame were allowed to correlate; and threat and coping were allowed to correlate. This model provided an adequate fit to the data, $X^{2}(9)=16.35, p=0.06, \mathrm{CFI}=0.997$, RM$\mathrm{SEA}=0.09$. The factor loadings are presented in Table I. As can be seen, all factor loadings were significant. Therefore, in the mediation analyses, we used a composite score consisting of the 7 subscales.

\section{Marital Expectations}

We initially tested whether the marital expectation variables loaded on to one latent construct. This model was not a good fit, $X^{2}(5)=41.85, p<0.001, \mathrm{CFI}=0.969$, RMSEA $=0.28$. Post hoc examination of the correlations between the error terms suggested that the 2 items assessing future happiness or satisfaction were uniquely correlated. In addition, the 2 items assessing predictions for divorce were also uniquely correlated. Therefore, the model was re-conducted with 1 latent variable of marital expectations, comprised of the 2 satisfaction variables (with the error terms correlated), the unhappiness variable, and the 2 divorce variables (with the error terms correlated). This model fit the data, $X^{2}(3)=4.86$, $p=0.18$, CFI $=0.998$, RMSEA $=0.08$ (see factor loadings in Table I). This model resulted in a significant improvement in model fit as compared to the 1st model with 1 latent factor without any correlated error terms, $X_{\text {diff }}^{2}(2)=37.69$. Therefore, for the mediation analyses, we included 1 composite variable composed of the 2 divorce items $(\alpha=0.82), 1$ composite variable composed of the 2 satisfaction variables $(\alpha=0.69)$, and the variable assessing predictions for future unhappiness in marriage on its own.

\section{Romantic Experiences}

We examined whether romantic experiences loaded onto 1 factor, indicated by the 6 items (asking someone out on a date, having gone on a bad date, having been turned down for a date, dated someone involved in another relationship, engaged in sexual relations with a date or romantic partner, and having had a date or romantic partner succeed in coercing sexual relations). This model did not fit the data, $X^{2}(9)=45.50, p=0.00, \mathrm{CFI}=0.975$, RMSEA $=0.21$. Post hoc examination of the correlations between the error terms suggested that the 3 items representing potentially risk-taking or maladaptive behavior (having dated someone involved in another relationship, having engaged in sexual relations, and having been coerced into sexual relations) were uniquely correlated. The model was re-conducted with these error terms correlated. This model provided an adequate fit to the data, $X^{2}(6)=10.04, p=0.12, \mathrm{CFI}=0.997$, RMSEA $=0.08$ (factor loadings presented in Table I) and it resulted in a significant improvement in model fit, $X_{\text {diff }}^{2}(3)=35.46$ as compared to the 1 st model without the error terms correlated. Because the potentially risk-taking variables were uniquely correlated with one another, for the mediation analyses we included one composite variable of risk-taking experiences (including having dated someone involved in another relationship, having engaged in sexual relations, and having been coerced into sexual relations) and the remaining 3 items separately.

\section{Correlations}

Table II presents zero-order correlations (with means and standard deviations) between all of the composite variables. As can be seen, virtually all of the variables were significantly associated with one another, although some of the marital expectations and romantic experiences were differentially correlated with perceptions of parental conflict, model of self, model of other, and neuroticism. This indicates that tests of mediation were appropriate in virtually all cases.

To examine whether parental perceptions of interparental conflict were associated with the outcome variables, we examined the correlations between both mothers' and fathers' perceptions of marital conflict and each of the three outcome measures. Neither fathers' perceptions nor mothers' perceptions of marital conflict were significantly associated with any of the outcome variables ( $r$ 's ranging from -0.18 to $0.05 \mathrm{~ns}$ ). Therefore, it is not parental perceptions of conflict that are important for marital expectations, but rather the adolescents' perceptions about interparental conflict. It should be noted that there was a significant correlation between mothers' perceptions of marital conflict and adolescents' perceptions of parental conflict $(r=0.23, p=0.03)$, although 


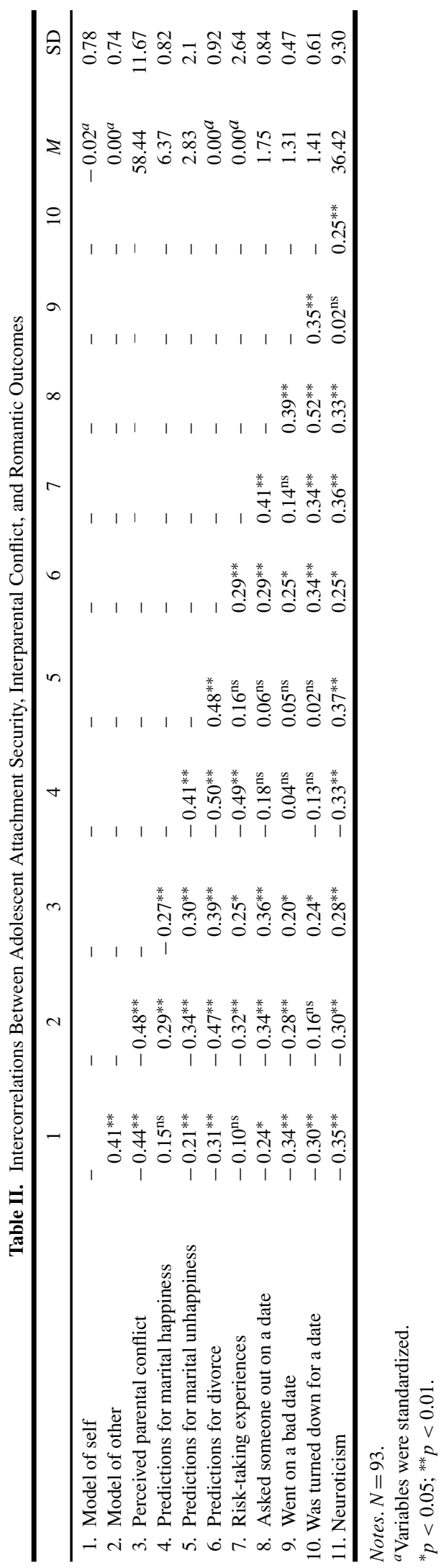


Table III. SEM Model with Attachment Security Variables as a Mediator Between Perceived Parental Conflict and Marital Expectations

\begin{tabular}{lcccc}
\hline \multicolumn{1}{c}{ Paths } & Model 1 & Model 2 & Model 3 & Model 4 \\
\hline Fit indices & & & & \\
$\quad X^{2}$ (df) & $4.40(3)$ & $6.22(6)$ & $0.75(3)$ & $1.07(3)$ \\
$\quad p$ value & 0.22 & 0.40 & 0.86 & 0.79 \\
CFI & 0.99 & 1.00 & 1.00 & 1.00 \\
$\quad$ RMSEA & 0.07 & 0.02 & 0.00 & 0.00 \\
Perceived parental conflict-> model of self & $-0.44^{* *}$ & $-0.44^{* *}$ & $-0.44^{* *}$ & $-0.38^{* *}$ \\
Perceived parental conflict-> model of other & $-0.48^{* *}$ & $-0.48^{* *}$ & $-0.48^{* *}$ & $-0.43^{* *}$ \\
Model of self-> marital satisfaction & $0.03^{\text {ns }}$ & & & \\
Model of self-> marital unhappiness & $-0.08^{\text {ns }}$ & & & \\
Model of self-> divorce & $-0.13^{\text {ns }}$ & & & $0.15^{\mathrm{ns}}$ \\
Model of other-> marital satisfaction & $0.28^{* *}$ & $0.29^{* *}$ & $0.21^{+}$ & $-0.19^{+}$ \\
Model of other-> marital unhappiness & $-0.30^{* *}$ & $-0.34^{* *}$ & $-0.25^{*}$ & $-0.35^{* *}$ \\
Model of other-> divorce & $-0.42^{* *}$ & $-0.47^{* *}$ & $-0.37^{* *}$ & $-0.13^{\mathrm{ns}}$ \\
Perceived parental conflict-> marital satisfaction & & & $-0.17^{\mathrm{ns}}$ & $0.13^{\mathrm{ns}}$ \\
Perceived parental conflict-> marital unhappiness & & & $0.18^{\mathrm{ns}}$ & $0.20^{+}$ \\
Perceived parental conflict-> divorce & & & $0.21^{*}$ & $0.21^{*}$ \\
Model of self $<->$ model of other & $0.25^{*}$ & $0.25^{*}$ & $0.25^{*}$ & $-0.24^{* *}$ \\
Neuroticism-> model of self & & & & $-0.18^{*}$ \\
Neuroticism-> model of other & & & & $0.28^{* *}$ \\
Neuroticism-> perceived parental conflict & & & & $-0.25^{*}$ \\
Neuroticism-> marital satisfaction & & & & $0.27^{*}$ \\
Neuroticism-> marital unhappiness & & & & \\
Neuroticism-> divorce & & & & \\
\hline
\end{tabular}

Notes. $\mathrm{CFI}=$ comparative fit index; RMSEA $=$ root mean square error of approximation .

${ }^{*} p<.05 ;{ }^{* *} p<.01$.

${ }^{+}$Marginally significant.

fathers' perceptions of marital conflict was not significantly correlated with children's perceptions of parental conflict ( $r=0.19 \mathrm{~ns})$. This suggests that despite the association between what adolescents perceived and what the mothers perceived, only the adolescents' perceptions are relevant for these outcome variables.

\section{Mediation analyses}

Does parent-adolescent attachment security mediate the association between perceptions of interparental conflict and adolescent romantic outcomes?

\section{Marital Expectations}

To examine whether attachment security mediated the association between parental conflict and marital expectations, we specified a model in which interparental conflict predicted model of self and model of other, which then predicted each of the 3 expectation variables: predictions for divorce, satisfaction, and unhappiness. The error terms for model of self and model of other were correlated, as were the error terms for the 3 marital expec- tations, reflecting the significant correlations in the CFA. This model fit the data (see Table III, Model 1). However, the paths from model of self to each of the 3 outcome variables were not significant, although the paths from model of other to the 3 outcome variables were significant. Therefore, we re-conducted the model eliminating the paths between model of self and the 3 outcome variables. This model fit the data (see Table III, Model 2).

We next included the direct paths from interparental conflict to each of the expectation variables to determine whether their inclusion improved the fit of this model. This model fit the data well (see Table III, Model 3). However, the difference in fit between this model with the direct paths included and the model without the direct paths was not significant $\left(X_{\text {diff }}^{2}(3)=5.47\right)$, indicating that the inclusion of the direct paths did not significantly improve model fit. As noted in Table III, the paths from model of other to predictions for divorce and predictions for unhappiness remained significant, and the path from model of other to predictions for satisfaction remained marginally significant. In sum, these results suggest that model of other at least partially mediated the association between perceptions of parental conflict and marital expectations. 
Table IV. SEM Model with Attachment Security Variables as a Mediator Between Perceived Parental Conflict and Romantic Experiences

\begin{tabular}{|c|c|c|c|c|}
\hline Paths & Model 1 & Model 2 & Model 3 & Model 4 \\
\hline \multicolumn{5}{|l|}{ Fit indices } \\
\hline$X^{2}(\mathrm{df})$ & $5.20(4)$ & $9.78(8)$ & $3.01(4)$ & $4.54(4)$ \\
\hline$p$-value & 0.27 & 0.28 & 0.56 & 0.34 \\
\hline CFI & 0.99 & 0.99 & 1.0 & 1.0 \\
\hline RMSEA & 0.06 & 0.05 & 0.00 & 0.04 \\
\hline Perceived parental conflict- $>$ model of self & $-0.44^{* *}$ & $-0.44^{* *}$ & $-0.44^{* *}$ & $-0.37^{* *}$ \\
\hline Perceived parental conflict- $>$ model of other & $-0.48^{* *}$ & $-0.48^{* *}$ & $-0.48^{* *}$ & $-0.43^{* *}$ \\
\hline Model of self- $>$ asked someone on a date- & $-0.12^{\mathrm{ns}}$ & & & \\
\hline Model of self- $>$ went on a bad date- & $-0.28^{* *}$ & $-0.31^{* *}$ & $-0.30^{* *}$ & $-0.34^{* *}$ \\
\hline Model of self- $>$ been turned down for a date & $-0.28^{* *}$ & $-0.26^{* *}$ & $-0.24^{* *}$ & $-0.22^{*}$ \\
\hline Model of self-> risk-taking behaviors & $0.04^{\mathrm{ns}}$ & & & \\
\hline Model of other-> asked someone out on a date & $-0.29^{* *}$ & $-0.29^{* *}$ & $-0.18^{* *}$ & $-0.13^{\mathrm{ns}}$ \\
\hline Model of other-> went on a bad date & $-0.16^{\mathrm{ns}}$ & & & \\
\hline Model of other- $>$ been turned down for a date & $-0.05^{\mathrm{ns}}$ & & & \\
\hline Model of other-> risk-taking behaviors & $-0.34^{* *}$ & $-0.30^{* *}$ & $-0.27^{*}$ & $-0.20^{*}$ \\
\hline Perceived parental conflict-> asked someone out & & & $0.28^{* *}$ & $0.23^{*}$ \\
\hline Perceived parental conflict- $>$ went on a bad date & & & $0.08^{\mathrm{ns}}$ & $0.08^{\mathrm{ns}}$ \\
\hline Perceived parental conflict- $>$ been turned down & & & $0.13^{\mathrm{ns}}$ & $0.09^{\mathrm{ns}}$ \\
\hline Perceived parental conflict-> risk-taking behaviors & & & $0.10^{\mathrm{ns}}$ & $0.05^{\mathrm{ns}}$ \\
\hline Model of self $<->$ model of other & $0.25^{*}$ & $0.25^{*}$ & $0.25^{*}$ & $0.21^{*}$ \\
\hline Neuroticism-> model of self & & & & $-0.24^{* *}$ \\
\hline Neuroticism-> model of other & & & & $-0.18^{*}$ \\
\hline Neuroticism $<->$ perceived parental conflict & & & & $0.28^{* *}$ \\
\hline Neuroticism- $>$ asked someone out on a date & & & & $0.23^{*}$ \\
\hline Neuroticism-> been turned down for a date & & & & $-0.10^{\mathrm{ns}}$ \\
\hline Neuroticism- $>$ went on a bad date & & & & $0.17^{\mathrm{ns}}$ \\
\hline Neuroticism-> risk-taking behaviors & & & & $0.29^{* *}$ \\
\hline
\end{tabular}

Notes. CFI $=$ comparative fit index; RMSEA $=$ root mean square error of approximation.

${ }^{*} p \leq .05 ;{ }^{* *} p \leq .01$.

${ }^{+}$Marginally significant.

We then added the neuroticism variable to this last model by including a path from neuroticism to perceptions of parental conflict, model of self, model of other, and the 3 outcome variables. This model was a good fit (see Table III, Model 4). As noted in Table III, of the 2 paths that were significant (model of other to divorce and model of other to unhappiness), 1 remained significant (model of other to divorce) while 1 became marginally significant (model of other to unhappiness). The path that was marginally significant (model of other to satisfaction) became non-significant. These findings suggest that while neuroticism did account for some of the associations, it was not significantly associated with predictions for divorce, the path that remained significant with model of other. Thus, neuroticism and model of other are relatively distinct variables with different effects on the marital expectation variables. In sum, after including neuroticism in the analyses, model of other still partially mediated the association between perceived parental conflict and predictions for divorce and predictions for marital unhappiness (marginally significant).

\section{Romantic Experiences}

To examine whether attachment security mediated the association between parental conflict and romantic experiences, we specified a model in which interparental conflict predicted model of self and model of other, which then predicted each of the 4 experience variables: asked someone out on a date, gone on a bad date, had someone turn you down for a date, and the risky experiences composite. The error terms for model of self and model of other were correlated, as were the error terms for the 4 romantic experience variables, reflecting the fact that they all loaded on 1 factor. This model fit the data, (see Table IV, Model 1), suggesting that a mediated model represents the data well. However, the paths between model of self and asking someone out on a date and the risky experience composite were not significant; and the paths between model of other and having gone on a bad date and having been turned down for a date were non-significant. Therefore, these paths were eliminated from the new model. The new model was a good fit (see Table IV, Model 2). 
We next included the direct paths from interparental conflict to each of the experience variables to determine whether their inclusion improved the fit of this model. This model fit the data well (see Table IV, Model 3). However, the difference in fit between this model with the direct paths included and the model without the direct paths was not significant $\left(X_{\mathrm{diff}}^{2}(4)=6.77\right)$, indicating that the inclusion of the direct paths did not significantly improve the model fit. The paths from model of self to having gone on a bad date and having been turned down for a date remained significant; as did the paths from model of other to having asked someone out on a date and the risky experience composite variable.

Finally, we added the neuroticism variable to this model by including paths between neuroticism and all of the other variables. This model was a good fit (see Table IV, Model 4). As noted in Table IV, of the 4 paths that were significant (model of self to having been turned down for a date and having gone on a bad date, and model of other to asking someone out on a date and the risk-taking experiences composite), 3 remained significant. The path from model of other to asking someone out on a date became non-significant. While neuroticism accounted for 1 association, it was not significantly associated with having gone on a bad date or having been turned down for a date, both of which remained significant in their association with model of self. Thus, neuroticism, model of other, and model of self are distinct variables with different effects on the romantic experience variables.

In sum, these analyses suggest that model of self and model of other partially mediated the association between perceptions of parental conflict and romantic experiences. In particular, a more negative model of self partially mediated the association between higher levels of perceived parental conflict and a higher frequency of having been turned down for a date and having gone on a bad date; whereas a negative model of other partially mediated the association between higher levels of perceived parental conflict and a higher frequency of risk-taking experiences. ${ }^{5,6}$

\footnotetext{
${ }^{5}$ We also tested an alternative mediation model with interparental conflict mediating the association between attachment security with parents and adolescent romantic outcomes, using SEM in the manner described in the results section. Results suggested that interparental conflict did not mediate the association between adolescent security and marital expectations and romantic experiences, but rather model of self and model of other retained direct associations with the romantic variables. This is not surprising given the cross-sectional nature of the data and the fact that this renders the 2 mediation models virtually identical from a statistical point of view.

${ }^{6}$ It is also possible that adolescent-parent attachment security and perceptions of parental conflict interact with one another such that, whether or not they are directly related to each other, 1 of them moderates the
}

\section{DISCUSSION}

This study was designed to examine associations between adolescent perceptions of interparental conflict, parent-adolescent attachment security, and adolescent marital expectations and romantic experiences. Previous research has suggested that interparental and parentadolescent factors influence adolescent functioning (e.g., Burman et al. 1987; Turner and Barrett, 1998). We proposed a mediation model in which attachment insecurity in parent-adolescent relations mediated the association between interparental conflict and marital expectations and romantic experiences. Overall, our results supported this prediction.

Specifically, we found that avoidance of intimacy mediated the association between perceived parental conflict and many of the romantic variables. Girls who reported more negative perceptions of parental conflict were less comfortable with closeness with their parents, which in turn was associated with expecting unhappiness and divorce in their own future marriages. The same was true for a number of the romantic experience variables, including asking someone out on a date and risk-taking experiences. The perception of high levels of interparental conflict manifests in the inability to feel close to parents which, in turn, is associated with adolescents' feeling pessimistic about their own future relationships, and engaging in approach-oriented and risky romantic experiences. These findings are consistent with the view that perceiving conflict in the parents' marriage might lead adolescents to view the parents negatively or to experience them as unavailable (if their energies are tied up in the conflict rather than the adolescent), which then manifests in low levels of closeness with the parents. The lack of closeness in the parent-child relationship may result in adolescents looking elsewhere for closeness, yet not believing that relationships will ultimately work out. Unfortunately, this process may set-up a self-fulfilling prophecy: adolescents seek out closeness in maladaptive ways, only to have their pessimistic beliefs confirmed. Of course this speculation

\footnotetext{
association between the other one and the romantic outcome variables In order to address this possibility, we tested moderation as an alternative model. Specifically, we examined whether perceived parental conflict and adolescent-parent attachment security interacted to predict the romantic outcomes. In order to examine if any of the variables served as a moderator, we first conducted individual regression analyses as suggested by Aiken and West (1991). If we had conducted these analyses in SEM, the model would be saturated, which would not allow us to test model fit. Because there were a total of 14 separate regression analyses, we conducted a Bonferroni correction and used a stricter $p$ value of 0.004 . None of the interactions were significant, indicating that neither model of self, model of other, nor perceptions of parental conflict served as a moderator (Table I).
} 
would need to be confirmed empirically. However, it is consistent with the rejection-sensitivity model presented earlier in which adolescents who are rejection-sensitive expect rejection from others and then actually experience rejection in their romantic experiences (Downey et al., 1999).

The other attachment dimension, anxiety about abandonment, also played a mediating role. Specifically, girls with more negative perceptions about interparental conflict were more afraid of being rejected and unloved by their parents, which in turn was associated with reporting having been turned down for a date and having gone on a bad date. This suggests 1 st that perceiving parental marital conflict might instill a fear of rejection in the adolescent, possibly because it might signal to the adolescent the potential loss of a parent's attention. Second, this potential loss of the parent may manifest in anxiety about rejection in the parent-child relationship, which results in experiences reflective of rejection in adolescents' romantic relationships. Unfortunately, we were unable to determine whether girls actually had these rejecting experiences or simply perceived them as such. Either way, however, these early experiences/perceptions may get built into developing schemas about the self and relationships, which could have a negative effect on functioning in the future.

The present findings are consistent with prior research suggesting that parent-adolescent relations mediate the association between interparental conflict and adolescent adjustment (e.g., Davies et al., 2002). In particular, the emotional security hypothesis posits that marital conflict may increase the negativity of parent-child interactions (i.e., lead to parental rejection), or it may decrease parental involvement and emotional availability because the parent is emotionally occupied by the conflict (Davies and Cummings, 1994). These negative parentchild relations then have implications for children's shortterm and long-term functioning (Cummings and Davies, 1995; Davies et al., 2002). In fact, data consistent with the emotional security hypothesis have yielded similar findings for adolescent romantic outcomes. For example, perceived interparental conflict is associated with adolescents' poor conflict resolution strategies with romantic partners, (Reese-Weber and Bertle-Haring, 1998), and this association is mediated by parent-adolescent conflict resolution strategies. Thus, the results of the current study provide further support for the theory that interparental relations may influence adolescent outcomes, specifically romantic functioning, through the parent-adolescent relationship.

While the results indicated that the attachment insecurity dimensions played a mediating role in many of the analyses, there are other notable findings. First, in the final mediation models with neuroticism included, higher levels of perceived parental conflict maintained a marginally significant association with predictions for divorce and a significant association with asking someone out on a date. These findings are important because they suggest that perceived parental conflict did have a direct effect on some of the outcome variables, which is consistent with prior research. For example, evidence suggests that adolescents who perceive a lot of interparental conflict or who have divorced parents, are more likely to exhibit maladaptive conflict resolution strategies or get divorced themselves (e.g., Reese et al., 1995). This is consistent with the marginally significant association in our sample between perceived parental conflict and adolescent predictions for divorce. In terms of asking someone out on a date, it appears that perceiving higher levels of parental conflict leads to adolescents seeking attention from a potential romantic partner, and that parental conflict is more important for this item than is parent-adolescent attachment insecurity. Research suggests that females from divorced families often marry at younger ages (Hetherington et al., 1978). Similarly, our data suggested that perceiving conflict between parents may have influenced adolescent females' approach-oriented behavior in terms of seeking out a romantic partner.

Second, the final models with neuroticism included yielded results suggesting that higher levels of neuroticism were associated with lower levels of predicted marital satisfaction, higher levels of predicted marital unhappiness, a higher frequency of asking someone out on a date, and a higher frequency of risk-taking behaviors. While there is little research examining neuroticism and adolescent romantic functioning, findings from the adult literature suggest that higher levels of neuroticism are associated with marital dissatisfaction (e.g., Leonard and Roberts, 1998) and that neuroticism is a strong predictor of negative marital outcome (Kelly and Conley, 1987). In addition, neuroticism has been linked with higher frequency of sexual risk-taking behaviors among adults (Hoyle et al., 2000). Our findings suggest that neuroticism may be linked with similar aspects of maladaptive romantic and sexual functioning in adolescence, a possibility that future research should explore.

The present findings add to the current literature in several important ways. First, as noted earlier, this study adds support to the existing literature suggesting that quality of the marital relationship (e.g., conflict, satisfaction, communication) influences adolescent romantic outcomes through the parent-adolescent relationship (e.g., Scharf and Mayseless, 2001, Martin, 1990). The majority of the other studies in this research area examine romantic outcome variables of adolescents who are 
currently involved in a romantic relationship. Interestingly, our findings suggested that the same mechanism of influence, attachment security, held true for adolescents' predictions about future marital happiness and current romantic experiences, which are variables that do not require involvement in a romantic relationship. Thus, the quality of the parental relationship and the parent-adolescent relationship appeared to affect adolescent romantic beliefs and experiences regardless of adolescent romantic relationship status. This is particularly important because it highlights the influence of these family variables for both cognitive (i.e., predictions about future marital happiness) and behavioral aspects of adolescent romantic functioning, and suggests that before adolescents are even involved in serious romantic relationships, the quality of their parents' relationship and their own relationship with their parents may influence their romantic lives and their expectations for their future romantic lives.

Second, the differential influence of the 2 attachment security dimensions on the romantic outcome variables allows us to draw more specific conclusions about the mechanism of influence of attachment security. Although previous research has suggested that adolescents' attachment security with parents may guide their expectations for romantic relationships over time (e.g., Roisman et al., 2001), this research does not speak to the mechanisms by which insecurity may be related to particular maladaptive romantic schemas or behaviors. Furthermore, findings from attachment research often fall prey to the criticism that "all good things go together," because they do not identify the conditions under which specific aspects of attachment security are associated with different outcomes (Waters and Dean, 1985). Our study actually identifies different dimensions of security as being particularly important for different romantic outcome variables. This is important because it enhances our understanding of the specific attachment mechanisms through which parental factors influence adolescent romantic functioning.

Two additional strengths of this study are noteworthy. First, we utilized both self-report and interview measures of attachment security, decreasing the likelihood that our findings are due to method variance. Second, we were able to rule out an important alternative hypothesis. Specifically, after a measure of neuroticism was included in our analyses, our results largely remained, which ruled out the possibility that this variable explains all the findings.

Despite these strengths, the present findings should be interpreted with the following in mind. First, because the data are cross-sectional, statements about causation or temporal ordering cannot be made. Longitudinal research is necessary to determine the extent to which family factors actually lead to maladaptive romantic outcomes.
Second, the present study used single-item measures as the romantic outcome variables. It would be useful to have multi-item standardized measures to assess marital expectations and romantic experiences, but such measures do not yet exist. Third, there was a limited range of responses for the romantic experience measures. It is possible that this restricted range limited our ability to detect associations. Fourth, it is also important to note that we used a somewhat limited range of marital expectations and romantic experiences. Future research would benefit from examining additional maladaptive romantic experiences in order to assess whether these findings are specific to the particular items in this study.

Finally, our sample size consisted of 7th and 8th grade girls from a few schools in the greater Buffalo area. This limits our ability to generalize our findings to all girls in this age range because demographic factors may influence the results. In addition, we do not know if these results can be generalized to boys, older adolescents, adolescents from divorced parents, or adolescents from a different socioeconomic bracket. Future research would benefit from studying a broader sample of adolescents under different demographic conditions. In addition, while our sample size was relatively low, Bentler and Chou (1987) noted that structural equations modeling requires 5-10 participants per variable. We met this suggestion with both the marital expectations model (necessitating 80 participants) and the romantic experiences model (necessitating 90 participants).

Related to the previous points, some may argue that the romantic outcome variables that we used may not be indicative of what will actually happen in the future. Although the direct link between adolescent and adult romantic functioning will need to be documented, we suggest that adolescents' marital expectations and romantic experiences have the potential to contribute to the relational schemas that adolescents' develop and, consequently, to their adult romantic functioning. As such, studying the predictors of adolescent romantic functioning is important (see also Scharf and Mayseless, 2001; Collins, 2003).

In addition, although the particular romantic experiences examined in this study do not necessarily represent aspects of a close, intimate relationship with a romantic partner (e.g., an attachment relationship), they are experiences that are considered to be maladaptive, risk-taking, or rejecting and, as such, are important targets of focus. Furthermore, these experiences may be good indicators of romantic activity in early adolescence, since long-term romantic relationships are not typical during this time period. Related to this, at the outset we were uncertain about whether the non-risk taking experiences would be 
maladaptive. Based on the findings, and on the correlations between the romantic experiences, it appears that these experiences might be maladaptive. This may be because these items represent either approach oriented experiences or potentially rejecting experiences. Specifically, asking someone out on a date, having gone on a bad date, and having been turned down for a date may be maladaptive because 13 years old girls may not have the emotional capacities to deal with these experiences. This is consistent with data examining the developmental stages of adolescent romantic functioning which posits that the romantic encounters of early and middle adolescents tend to revolve around the peer group, rather than a dyadic setting (Connolly et al., 1996).

In conclusion, this study is one of the first in a developing field of family influences on adolescent romantic views and experience. Our findings fill an important gap in the literature examining interparental factors and parent-child factors on child or adolescent outcomes (e.g., Fauber et al., 1990; Davies et al., 2002), as they speak directly to adolescent marital expectations and romantic experiences, rather than overall adjustment. Moreover, the current study adds to the existing literature examining family influences on adolescent romantic functioning (e.g., Scharf and Mayseless, 2001; Furman et al., 2002) by identifying particular aspects of family relationships and a specific path of influence. We have provided initial support that the association between perceived parental conflict and marital expectations and romantic experiences is mediated through an insecure adolescent-parent relationship, primarily avoidance of intimacy. This may have implications for future romantic functioning in late adolescence and adulthood. We hope that these findings encourage other researchers to continue to examine the specific mechanisms by which interparental factors and parent-adolescent factors influence adolescent marital expectations and romantic experiences.

\section{ACKNOWLEDGMENTS}

This research was supported in part by a grant from the Templeton Foundation to the third author. The authors would like to thank the staff of the Study of Teen and Adult Relationships at the State University of New York at Buffalo, and all of the families who generously gave their time to participate in these projects.

\section{REFERENCES}

Aiken, L. S., and West, S. G. (1991). Multiple Regression: Testing and Interpreting Interactions. Sage, Thousand Oaks.
Arbuckle, J. L. (1997). Amos User's Guide Version 3.6. Smallwaters, Chicago.

Baron, R. M., and Kenny, D. A. (1986). The moderator-mediator variable distinction in social psychological research: Conceptual, strategic and statistical considerations. J. Personal. Soc. Psychol. 51: 1173-1182.

Bartholomew, K. (1998). The Family and Peer Attachment Interview. Unpublished manuscript. Simon Fraser University.

Bartholomew, K., and Horowitz, L. M. (1991). Attachment styles among young adults: A test of a four-category model. J. Personal. Soc. Psychol. 61: 226-244.

Bentler, P. M., and Chou, C. (1987). Practical issues in structural modeling. Soc. Methods Res. 16: 78-117.

Berscheid, E. (1999). The greening of relationship science. Am. Psychol. 54: 260-266.

Bickam, N. L., and Fiese, B. H. (1997). Extension of the Children's Perceptions of Interparental Conflict Scale for use with late adolescents. J. Fam. Psychol. 11: 246-250.

Bowlby, J. (1969). Attachment and Loss: Volume I. Attachment. Hogarth, London.

Burman, B., John, R. S., and Margolin, G. (1987). Effects of marital and parent-child relations on children's adjustment. J. Fam. Psychol. 1: 91-108.

Collins, W. A. (2003). More than myth: The developmental significance of romantic relationships during adolescence. J. Res. Adolesc. 13: $1-24$.

Collins, N. L., Cooper, M. L., Albino, A., and Allard, L. (2002). Psychosocial vulnerability from adolescence to adulthood: A prospective study of attachment style differences in relationship functioning and partner choice. J. Personal. 70: 965-1008.

Collins, N. L., and Read, S. J. (1990). Adult attachment, working models, and relationship quality in dating couples. J. Personal. Soc. Psychol. 58: 644-663.

Collins, W. A., and Sroufe, L. A. (1999). Capacity for intimate relationships: A developmental construction. In Furman, W., Brown, B.B., and Feiring,C. (eds.), The Development of Romantic Relationships in Adolescence. Cambridge University Press, New York, pp. 235-265.

Conger, R. D., Cui, M., Bryant, C. M., and Elder, G. H. (2000). Competence in early adult romantic relationships: A developmental perspective on family influences. J. Personal. Soc. Psychol. 79: 224-237.

Connolly, J., Ben-Knaz, R., Goldberg, A., and Craig, W. (1996). Early Adolescent's Conceptions of Romantic Relationships. Poster presented at the biennial meeting of the Society for Research on Adolescence, Boston.

Cummings, E. M., and Davies, P. T. (1995). The impact of parents on their children: An emotional security hypothesis. Ann. Child Dev. 10: 167-208.

Davies, P. T., and Cummings, E. M. (1994). Marital conflict and child adjustment: An emotional security hypothesis. Psychol. Bull. 116: 387-411.

Davies, P. T., Harold, G. T., Goeke-Morey, M. C., and Cummings, E. M. (2002). Child emotional security and interparental conflict. Monographs of the Society for Research in Child Development 67: vii-113.

Davila, J., Steinberg, S. J., Kachadourian, L., Cobb, R., and Fincham, F. (2004). Romantic involvement and depressive symptoms in early and late adolescence: The role of a preoccupied relational style. Pers. Relations. 11: 161-178.

Downey, G., Bonica, C., and Rincon, C. (1999). Rejection sensitivity and adolescent romantic relationships. In Furman,W., Brown, B. B., and Feiring, C. (eds.), The Development of Romantic Relationships in Adolescence. Cambridge University Press, New York, pp. 148-174.

Downey, G., Freitas, A., Michaelis, B., and Khouri, H. (1998). The self-fulfilling prophecy in close relationships: Do rejection sensitive women get rejected by their partners? J. Personal. Soc. Psychol. 75: $545-560$.

Emery, R. E. (1982). Interparental conflict and the children of discord and divorce. Psychol. Bull. 92: 310-330.

Fauber, R., Forehand, R., Thomas, A. M., and Wierson, M. (1990). A mediational model of the impact of marital conflict on adolescent adjustment in intact and divorced families: The role of disrupted parenting. Child Dev. 61: 1112-1123. 
Furman, W., Simon, V. A., Shaffer, L., and Bouchey, H. A. (2002). Adolescents' working models and styles for relationships parents, friends, and romantic partners. Child Dev. 73: 241-255.

Furman, W., and Shaffer, L. (2002). Conflict and Conflict Resolution in Adolescent Romantic Relationships. Poster presented at the 9th biennial meeting of the Society for Research in Adolescence, New Orleans, LA.

Furman, W. and Wehner, E. A. (1994). Romantic views: Toward a theory of adolescent romantic relationships. In Montemayor, R., Adams, G. R., and Gullota, G.P. (eds.), Advances in Adolescent Development: Relationships during adolescence, Sage, Thousand Oaks, CA, Vol. 6, pp. 168-175.

George, C., Kaplan, N., and Main, M. (1985). The Adult Attachment Interview. Unpublished manuscript, University of California at Berkeley.

Goldberg, L. R. (1992). The development of markers for the Big-Five factor structure. Psychol. Assess. 4: 26-42.

Gray, M. R. and Steinberg, L. (1999). Adolescent romance and the parent-child relationships: A contextual perspective. In Furman, W., Brown, B. B., and Feiring, C. (eds.), The Development of Romantic Relationships in Adolescence. Cambridge University Press, New York, pp. 235-265.

Grych, J. H., Seid, M., and Fincham, F. D. (1992). Assessing marital conflict from the child's perspective: The children's perception of interparental conflict scale. Child Dev. 63: 558-572.

Harold, G. T., Fincham, F. D., Osbourne, L. N., and Conger, R. D. (1997). Mom and dad are at it again: Adolescent perceptions of marital conflict. Dev. Psychol. 33: 333-350.

Hazan, C., and Shaver, P. (1987). Romantic love conceptualized as an attachment process. J. Personal. Soc. Psychol. 52: 511-524.

Hetherington, E. M., Cox, M., and Cox, R. (1978). The development of children in mother-headed families. In Hoffman, H., and Reiss, D. (eds.), The American family: Dying or Developing? Plenum Press, New York, pp. 117-156.

Howes, P., and Markman, H. J. (1989). Marital quality and child functioning: A longitudinal investigation. Child Dev. 60: 1044-1051.

Hoyle, R. H., Fejfar, M. C. and Miller, J. D. (2000). Personality and sexual risk-taking: A quantitative review. J. Personal. 68: 1203-1231.

Kelly, E. L., and Conley, J. J. (1987). Personality and compatibility: A prospective analysis of marital stability and marital satisfaction. $J$. Personal. Soc. Psychol. 52: 27-40.

Kobak, R. R., and Sceery, A. (1988). Attachment in late adolescence: Working models, affect regulation, and representations of self and others. Child Dev. 59: 135-146.

Leonard, K. G., and Roberts, L. J. (1998). Marital aggression, quality, and stability in the first year of marriage: Findings from the Buffalo Newlywed Study. In Bradbury, T. N. (ed.), The Developmental Course of Marital Dysfunction. Cambridge University Press, New York, pp. 44-73.

Long, B. (1986). Parental discord vs. family structure: Effects of divorce on the self-esteem of daughters. J. Youth Adolesc. 15: 19-27.

Long, B. (1987). Perceptions of parental discord and parental separation in the United States: Effects of daughters' attitudes toward marriage and courtship progress. J. Soc. Psychol. 127: 557-582.
Martin, B. (1990). The transmission of relationships difficulties from one generation to the next. J. Youth Adolesc. 19: 181-199.

Murray, S. L., Holmes, J. G., and Griffin, D. W. (1996). The benefits of positive illusions: Idealization and the construction of satisfaction in close relationships. J. Personal. Soc. Psychol. 70: 79-98.

Owen, M. T., and Cox, M. J. (1997). Marital conflict and the development of infant-parent attachment relationships. J. Fam. Psychology 11: $152-164$.

Reese, M., Creasey, G., Bergner, R., Criss, M., and Ottlinger, K. (1995). Late Adolescent Conflict Resolution as a Function of Previous Exposure to Interparent Conflict. Paper presented at the biennial meetings of the Society for Research in Child Development, Indianapolis.

Reese-Weber, M., and Bartle-Haring, S. (1998). Conflict resolution styles in family subsystems and adolescent romantic relationships. J. Youth Adolesc. 27(6): 735-752.

Roisman, G. I., Madsen, S. D., Henninghausen, K. H., Sroufe, L. A., and Collins, W. A. (2001). The coherence of dyadic behavior across parent-child and romantic relationships as mediated by the internalized representation of experience. Attach. Human Dev. 3: 156-172.

Saucier, G. (1994). Mini-markers: A brief version of Goldberg's unipolar Big-five markers. J. Personal. Assess. 63: 506-516.

Saucier, G. (2000). Isms and the structure of social attitudes. J. Personal Soc. Psychol. 78: 366-385.

Scharf, M. and Mayseless, O. (2001). The capacity for romantic intimacy: exploring the contribution of best friend and marital and parental relationships. J. Adolesc. 24: 379-399.

Shaver, P. R., and Mikulincer, M. (2004). What do self-report measures of attachment assess? In Rholes, W. S., and Simpson, J. A. (eds.), Adult Attachment: Theory, Research, and Clinical Applications. Guilford Press, New York, pp. 17-54.

Shulman, S., and Scharf, M. (2000). Adolescent romantic behaviors and perceptions: Age- and gender-related differences, and links with family and peer relationships. J. Res. Adolesc. 10: 99-118.

Simon, R. W., and Marcussen, K. (1999). Marital transitions, marital beliefs, and mental health. J. Health Soc. Behav. 40: 111-125.

Turner, C. M., and Barrett, P. (1998). Adolescent adjustment to perceived marital conflict. J. Child Fam. Stud. 7: 499-513.

Waters, E., Crowell, J., Elliott, M., Corcoran, D., and Treboux, D. (2002). Bowlby's secure base theory and the social/personality psychology of attachment style: Work(s) in progress. Attach. Human Dev. 4: 230-242.

Waters, E., and Dean, K. (1985). Defining and assessing individual differences in attachment relationships: Q-sort methodology and the organization of behavior in infancy and early childhood. In Bretherton, I., and Waters, E. (eds.), Monographs of the Society for Research in Child Development, Vol. 50, pp. 41-65.

Watson, D., and Clark, L. A. (1984). Negative affectivity: The disposition to experience aversive emotional states. Psychol. Bull. 96: 465-490.

Welsh, D. P., Grello, C. M., and Harper, M. S. (2003). When love hurts: Depression and adolescent romantic relationships. In Florsheim, P. (ed.), Adolescent Romantic Relations and Sexual Behavior: Theory, Research, and Practical Implications. Lawrence Erlbaum, Mahwah, NJ . 
Copyright of Journal of Youth \& Adolescence is the property of Springer Science \& Business Media B.V. and its content may not be copied or emailed to multiple sites or posted to a listserv without the copyright holder's express written permission. However, users may print, download, or email articles for individual use. 